\title{
Orphenadrine Citrate
}

National Cancer Institute

\section{Source}

National Cancer Institute. Orphenadrine Citrate. NCI Thesaurus. Code C47641.

The citrate salt form of orphenadrine with a muscle relaxant property. Although the mechanism of action has not been fully elucidated, orphenadrine citrate appears to block cholinergic receptors, thereby interfering with the transmission of nerve impulses from the spinal cord to the muscles. It does not produce myoneural block, nor does it affect crossed extensor reflexes. 